\title{
artigo
}

\section{Vivência do enfermeiro frente ao cuidado a pacientes oncológicos no hospital de clínicas Dr. Alberto Lima em Macapá-AP}

\author{
Experience of the nurse in front of care for oncological patients in the hospital of clinics Dr. Alberto Lima in Macapá-AP
} Experiencia de la enfermera frente a la atención de pacientes oncológicos en el hospital de clínicas Dr. Alberto Lima en Macapá-AP

\section{RESUMO}

O câncer é um conjunto de mais de 100 doenças que possuem em comum o crescimento e a multiplicação desordenada de células. A enfermagem que atua constantemente com o paciente, necessita saber lidar com suas emoções e ajudar no enfrentamento do sofrimento do mesmo ao ser diagnosticado com câncer. Objetivo conhecer as emoções dos profissionais de enfermagem frente ao paciente oncológico atendido no hospital de clinicas Dr. Alberto Lima (HCAL) em Macapá-AP, utilizando o Inventário de estratégias de Coping. Método: Foi um estudo de natureza descritiva, pesquisa de campo, quanti-qualitativa. Resultados: A totalidade dos enfermeiros entrevistados utilizou as estratégias de coping, sendo as estratégias de resolução de problemas $(83,3 \%)$ e reavaliação positiva $(73,3 \%)$ as mais utilizadas. Conclusão: Isso demostra que os enfermeiros planejam suas ações para encontrar uma melhor solução para cada problema e também procuram crescer e mudar como pessoa a partir de situações conflitantes.
\end{abstract}

DESCRITORES: Câncer. Enfermagem, Pacientes, Emoções.

\section{ABSTRACT}

Cancer is a set of more than 100 diseases that have in common, the growth and disorderly multiplication of cells. Nurses who work constantly with patients need to know how to deal with their emotions and help them cope with their suffering when diagnosed with cancer. Objective to know the emotions of nursing professionals towards the cancer patient treated at the Dr. Alberto Lima clinical hospital (HCAL) in Macapá-AP, using the Coping Strategies Inventory. Method: This study was descriptive, field research, quantitative and qualitative. Results: All nurses interviewed used coping strategies, with problem solving strategies (83.3\%) and positive reevaluation (73.3\%) being the most used. Conclusion: This shows that nurses plan their actions to find a better solution for each problem and also try to grow and change as a person from conflicting situations.

DESCRIPTORS: Cancer. Nursing, Patients, Emotions.

\section{RESUMEN}

El cáncer es un conjunto de más de 100 enfermedades que tienen en común el crecimiento y la multiplicación desordenada de las células. Las enfermeras que trabajan constantemente con los pacientes necesitan saber cómo lidiar con sus emociones y ayudarlos a afrontar su sufrimiento cuando se les diagnostica cáncer. Objetivo conocer las emociones de los profesionales de enfermería hacia el paciente oncológico atendido en el hospital clínico Dr. Alberto Lima (HCAL) de Macapá-AP, utilizando el Inventario de Estrategias de Afrontamiento. Método: Este estudio fue descriptivo, de campo, cuantitativo y cualitativo. Resultados: Todas las enfermeras entrevistadas utilizaron estrategias de afrontamiento, siendo las estrategias de resolución de problemas $(83,3 \%$ y la reevaluación positiva $(73,3 \%$ ) las más utilizadas. Conclusión: Esto demuestra que las enfermeras planifican sus acciones para encontrar una mejor solución a cada problema y también tratan de crecer y cambiar como persona a partir de situaciones conflictivas.

DESCRIPTORES: Cáncer. Enfermería, Pacientes, Emociones.

RECEBIDO EM: 30/10/2020 APROVADO EM: 09/11/2020 


\section{Ana Karoline Pinto dos Santos}

Enfermeira. Graduada pela Faculdade Madre Tereza

ORCID: 0000-0002-84742866

\section{Fabiana da Cruz Coelho}

Enfermeira. Graduada pela Faculdade Madre Tereza

ORCID: 0000-0002-2485-8699

\section{Marivanda Conceição da Fonseca}

Enfermeira, especialista em Urgencia/Emergencia e UTI. Graduada pela Faculdade Madre Tereza

ORCID: 0000-0001-6511-1527

\section{Ildilane Suelem Rodrigues Carvalho}

Orientadora, Docente do Curso de Enfermagem da Faculdade Madre Tereza. Mestranda em Ciencias da Saúdem (UNIFAP). ORCID: 0000-0001-8418-4852

\section{INTRODUÇÃO}

\section{0} câncer é uma doença evidenciada pelo crescimento anormal e desordem das células que atingem indivíduos sem distinção de gênero, idade, cultura e situação socioeconômica ${ }^{1}$.

Kiuser et al. ${ }^{2}$ diz que o lado emocional do profissional e do paciente com câncer ficam abalados, o profissional admite que além do cuidado técnico deve também se esforçar para cuidar do lado psicológico desse paciente, mesmo não sendo capacitado nesse sentido. Diante disso, é importante ressaltar que o enfermeiro também deve ser assistido por profissionais capacitados para ajudá-lo no sentido de conviver com o sofrimento diário do tratamento do câncer e as perdas frequentes

Para Menegócio, Rodrigues, Teixeira ${ }^{3}$ os princípios da humanização, demonstra a importância de uma assistência ampliada e não baseada apenas em questões técnicas. Desse modo, apresentam a relação de afetividade (pequenos gestos como toque, de emoções perturbadoras ${ }^{4}$.

A justificativa desse estudo é dada pela importância que é direcionada ao câncer, pois é a segunda causa de morte no mundo, só fica atrás das doenças cardiovasculares, além de ser uma patologia com grande taxa de mortalidade, ainda tem que levar em consideração os desgastes emocionais e físicos infligidos pelas neoplasias, merecendo atenção especial por parte dos profissionais de enfermagem no sentido de diminuir o sofrimento do paciente, pois são eles que estão mais próximos do mesmo por um período maior, o que os tornam habilitados para prestar atendimento adequado, saber compreender e apoiar todas as suas necessidades, no período do adoecimento. Por este motivo faz-se necessário o estudo de estratégias de coping utilizadas por profissionais como forma de aliviar o estresse do cotidiano ao cuidado a paciente com câncer. $\mathrm{O}$ problema desse trabalho foi saber qual a percepção dos enfermeiros ao lidar com suas emoções ao prestar cuidados a esses pacientes?

O Objetivo desta pesquisa foi conhecer as emoções dos profissionais de enfermagem frente ao paciente oncológico atendido no hospital de clinicas Dr. Alberto Lima (HCAL) em Macapá-AP, utilizando o Inventário de estratégias de Coping, conforme detalhamento constante na metodologia.

\section{MÉTODO}

Este estudo foi de natureza descritiva, pesquisa de campo, quanti-qualitativa.

Foram critérios de exclusão não prestar assistência a pacientes oncológicos, o preenchimento inadequado de instrumento de coleta de dados, a desistência ou não aceitação em participar da pesquisa a qualquer momento desta e prestação de informações incompletas na coleta de dados e férias ou outro tipo de afastamento do serviço.

$\mathrm{O}$ instrumento utilizado nesta pesquisa foi o inventário de estratégia de coping.
As respostas de cada item foram anotadas em uma escala tipo Likert, que varia de zero (não usei essa estratégia), a três (usei em grande quantidade essa estratégia), na qual serão utilizados somente os itens que correspondem aos objetivos desta pesquisa, este invetario é composto por oito itens, são eles: Fator 1: Confronto; fator 2: Afastamento; fator 3: Autocontrole; fator 4: Suporte social; fator 5: Aceitação de responsabilidades; fator 6: Fuga-esquiva; fator 7: Resolução de problemas; fator 8: Reavaliação positiva 5 .

A coleta de dados deu-se após a autorização do hospital e aprovação do comitê de ética em pesquisa obedecendo aos preceitos da Resolução no 466/2012 do Conselho Nacional de Saúde que trata sobre pesquisa com seres humanos. Aprovado pelo parecer de $n^{\circ} 2.294 .739$ do CEP/ SEAMA. Participaram da pesquisa uma amostra de 30 enfermeiros atuantes nas clinicas médicas: feminina, masculina, cirúrgica, CDT, UTI e UNACON do Hospital de Clinicas Dr. Alberto Lima. A coleta de dados ocorreu a partir de 02/10 à 20/10/2017. Todos os participantes assinaram um Termo de Consentimento Livre e Esclarecido - TCLE, garantindo a estes o anonimato, precisão e imparcialidade do estudo, com sigilo e caráter confidencial das informações obtidas através de formulário e entrevista.

Logo, utilizou-se gráficos para apresentação dos resultados. Ainda como forma de análise dos dados buscou-se identificar na fala dos sujeitos informações referentes 


\section{artigo}

Santos, A.K.P.; Coelho, F.C.; Fonseca, M.C.; Carvalho, I.S.R.;

Experience of the nurse in front of care for oncological patients in the hospital of clinics Dr. Alberto Lima in Macapá-AP

a vivência do enfermeiro frente ao cuidado a pacientes oncológicos.

\section{RESULTADOS E DISCUSSÃO}

A assistência de enfermagem a pacientes oncológicos requer muita atenção do profissional de enfermagem, uma vez que estes prestam cuidados intensivos a pessoas com ou sem possibilidade de cura, pois a rotina do ambiente hospitalar e as vivências com os pacientes oncológicos e seus familiares causam desgaste a esses profissionais, e lidar com o acúmulo desses fatores causam o estresse ${ }^{6}$.

\section{Emoções despertadas na assistência a pacientes oncológicos.}

Elencamos as emoções que foram mencionadas pelos profissionais. Temos acima, as emoções citadas pelos enfermeiros em resposta à pergunta da entrevista. Descreva quais as emoções você sente ao cuidar de pacientes oncológicos?

Com isso, percebe-se que as emoções mais evidenciadas utilizada pelos profissionais foram: Empatia (20\%), Impotência $(23 \%)$ e Tristeza (43.3\%).

\section{Utilização das estratégias de coping para enfrentamento das emoções}

$\mathrm{Na}$ dificuldade de prestar assistência a pacientes com câncer deve-se procurar uma maneira de enfrentar determinadas situações estressoras, podem ser usadas formas de enfrentamento, que auxiliem e ajudem diante de uma situação de estresse, estratégias essas que ajudam o indivíduo a adaptar-se da melhor forma possível ao evento estressor, de maneira a reduzir ou minimizar essas situações ${ }^{7}$.

As repostas foram comparadas entre

\section{Gráfico 1: Emoções despertadas nos enfermeiros do HCAL Macapá/AP, ano 2017.}

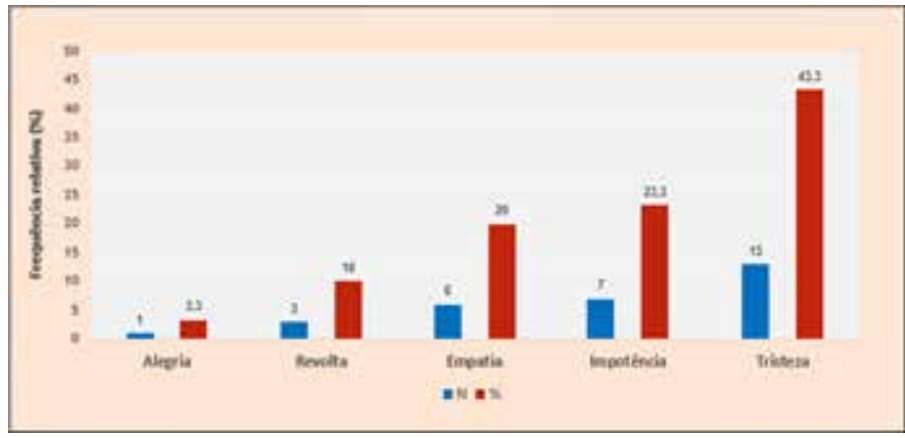

Fonte: Primária, 2017

*Tendência estatisticamente significante pelo Teste de Kolmogorov-Smirnov. (Ayres et al., 2007, p.121)

\section{Gráfico 2: Distribuição das Estratégias de coping, n=30 profissionais.}

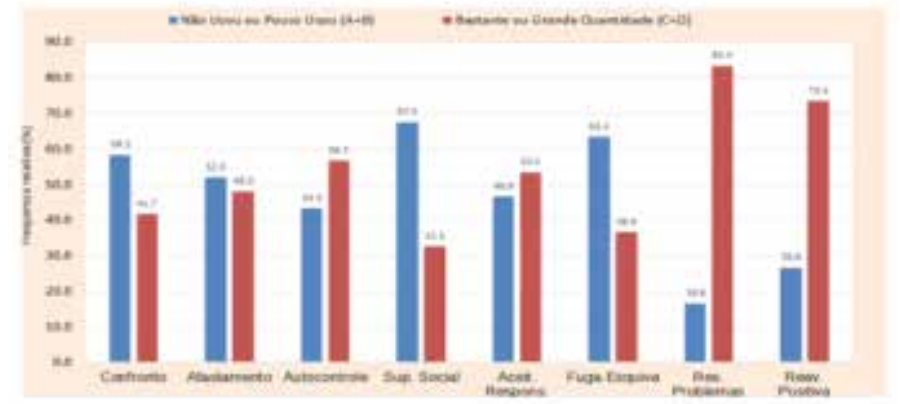

2 categorias: $(A+B)$ Não usou ou Usou pouco e $(\mathrm{C}+\mathrm{D})$ Usou bastante ou Grande quantidade e, constatou-se que houve tendência estatisticamente significante para:

a) Usou Bastante ou Muito a Resolução de Problemas (83.3\%), com $\mathrm{p}$-valor $=0.0005^{*}$.

b) Usou Bastante ou Muito a Reavaliação Positiva (73.3\%), com p-valor $=0.0176^{*}$.

O confronto está relacionado aos desafios enfrentados no cotidiano de situações estressantes, tal qual extravasar seus sentimentos (LAGES, et al, 2011). Nesta pesquisa ao utilizar essa estratégia (Gráfico 2), na classificação não usou ou pouco usou $(\mathrm{A}+\mathrm{B}) 58,3 \%$ e bastante ou grande quantidade $(\mathrm{C}+\mathrm{D})$ 41,6\%. Cabe salientar que a maioria evitar comportamentos com intenções de confronto diante da situação dita como estressante. Resultado evidenciado na voz do (ENF. 23).

(...) "as coisas são mais difíceis, então a gente tenta manter aquela imparcialidade, paciente aqui, eu tô aqui, aqui eu sou profissional $e$ ele paciente, procuro diferenciar as coisas".

De acordo com Damião et al.8 o afastamento corresponde à estratégia de não se deixar envolver emocionalmente e sempre ir em busca de distrações fora do ambiente hospitalar. Esse fator demostrado na (Gráfico 2), na classificação $(A+B) 52 \%$ não utiliza e $(C+D) 48 \%$ bastante e em grande quantidade. Este resultado mostra que os enfermeiros não negam ou se recusam ter proximidade com o fato desestruturante. Tal resultado mencionado na voz do (ENF 21).

(...) "foi assim muito marcante, ai eu fui ao velório, conversei com o marido dela, com os filhos dela, eu ia muito a casa dela... eu nunca imaginei ter uma relação assim".

Segundo Oliveira ${ }^{9}$ ter autocontrole significa não fazer nada apressadamente ou seguir um primeiro impulso, e também a capacidade de controlar suas emoções 
e desejos. $\mathrm{O}$ autocontrole (Gráfico 2), na classificação $(A+B) 43,3 \%$ não usou (C+D) $56,7 \%$ utiliza bastante. Diante disso, foi possível observar que o profissional tenta controlar suas emoções guardando seus sentimentos para si mesmo. Esclarecido melhor no relato do (ENF. 22).

(...) "não tem como pensar em sentimento, a sensação é de prestar o melhor cuidado possivel para aquele paciente, para minimizar o sofrimento dele... a gente sente... acaba pensando na vida um pouco mais... e ver, o paciente lutando pela vida. Mas o que a gente pode fazer? Tentar amenizar o sofrimento dele".

O suporte social está relacionado ao apoio encontrado nas pessoas e no ambiente, que ajuda o profissional a lidar com o efeito indesejado do estresse, que diz respeito a procurar apoio social e profissional, também apoio emocional em amigos e familiares 9 . Relacionado ao suporte social (Gráfico 2), na classificação $(A+B)$ evidenciou-se um percentual de $67,5 \%$ não utilizou da estratégia e na $(\mathrm{C}+\mathrm{D})$ apenas $32,5 \%$ utilizou. Confirmado na voz do (ENF. 28).

(...) "e ainda vem à carência do profissional psicólogo, que nós não temos".

O fator aceitação de responsabilidades é evidenciado pela aceitação da realidade no processo de lidar com situações estressantes e isso os estimula no enfrentamento de seus problemas de outra forma, entendendo que as coisas podem ser diferentes na próxima vez ${ }^{8}$. Relacionado a esse fator (Gráfico 2), na classificação (A+B) 46,6\% não usa e $(C+D) 53,4 \%$ utiliza bastante. Com esse resultado foi possível observar que o enfermeiro aceita a realidade e envolve-se no processo de lidar com as situações estressantes. A voz do (ENF. 17) demostra esse fator.

(...) "é o minimo que a gente pode fazer, oferecer o que a gente tem, $e$ dar atenção, e eu percebo que isso faz uma grande diferença e tanto no nosso trabalho, embora falte tanta coisa, mas você querer fazer, dar atenção isso pode ser um grande remédio".

\section{O fator aceitação de}

responsabilidades

é evidenciado

pela aceitação

da realidade no

processo de lidar

com situações

estressantes e isso

os estimula no

enfrentamento de

seus problemas

de outra forma,

entendendo que

as coisas podem

ser diferentes na

próxima vez
A fuga e esquiva é caracterizada como os esforços para distanciar-se ou evitar os fatores estressantes ${ }^{7}$. Esse fator (Gráfico $2)$, na classificação $(A+B)$ evidenciou- se $63,3 \%$ dos participantes da pesquisa não utiliza e na $(\mathrm{C}+\mathrm{D})$ somente $36,6 \%$ a utilizaram. Tal resultado demostra que os enfermeiros não fogem das dificuldades enfrentadas no seu dia a dia. Isso pode ser encontrado na citação do (ENF 25).

(...) "e eu lembro que me apeguei muito a ela... foi bem emocionante... quando cheguei ao plantão ela tinha ido a óbito".

Para Lages ${ }^{7}$ a resolução de problemas está relacionada à capacidade do individuo ter um planejamento adequado para encontrar soluções dos problemas específicos. No (Gráfico 6), observou-se que na classificação $A+B$ foi representado por 16,6\% e C+D 83,3\% utilizam essas estratégias. Esse resultado mostra que os enfermeiros têm planejamento adequado para enfrentar os eventos estressores. Tal fator pode ser frisado na fala do (ENF 24) (...) "então se nós profissionais daqui não começarmos a fazer por conta própria, não sai, os improvisos."

A reavaliação positiva diz respeito à forma de reinterpretar, mudar e crescer como pessoa após as experiências vividas a partir das situaçóes conflitantes podendo apresentar características religiosas?. Tal fator (Gráfico 6), na classificação $(A+B)$ $26,6 \%$ não usam e na $(C+D) 73,3 \%$ usam essa estratégia. Esse resultado mostra que os profissionais procuram melhorar como pessoa a partir de situações conflitantes. Podemos explicitar nos relatos dos enfermeiros 5 e 27 respectivamente.

(...) "num plantão perto do óbito, o paciente me chamava para que fizesse medicação para aliviar sua dor, peguei sua mão e rezei para que Deus lhe desse um final tranquilo". (...) "paciente estava muito aflita, porque... antes de morrer conversei com ela, fiz uma oração com ela, depois ela ficou mais tranquila e ela chegou a falecer na mesma noite. 2uando a gente faz alguma 
coisa a gente sente que cumpriu o nosso papel."

\section{CONCLUSÃO}

Os resultados dessa pesquisa demostram que as emoções citadas pelos profissionais, identificou-se as que mais se evidenciaram: Empatia (20\%), impotência (23\%) e tristeza (43.3\%). Esses resultados demonstram que a prática da enfermagem apesar de ser fundamentada no conhecimento técnico cientifica sofre também interferências dos sentimentos que o enfermeiro traz no seu dia-a-dia.

Na primeira análise ao utilizar a estratégia de coping observou-se que ao classificar as categorias não usou, usou pouco, usou bastante, e grande quantidade houve tendência significante para Usou bastante Resolução de Problemas (52,2\%).

$\mathrm{Na}$ segunda análise constatou-se que os enfermeiros utilizaram os oitos fatores de coping. Ao determinar as estratégias as formas de enfretamento mais utilizadas pelos enfermeiros foram reso-

\section{Os resultados}

dessa pesquisa

demostram que as

emoções citadas

pelos profissionais,

identificou-se

as que mais se

evidenciaram:

Empatia (20\%), impotência (23\%) e tristeza $(43.3 \%)$. lução de problemas $(83,3 \%)$ e reavaliação positiva (73,3\%).

Diante disso, entende-se que eles procuram um planejamento adequado para lidar com as situações de estresse, ao utilizar formas positivas para solucionar os problemas, na tentativa de através de planos e alternativas diminuir a carga emocional. Desde modo, o conhecimento dessas estratégias pode ajudar nas necessidades do enfermeiro em amenizar o seu sofrimento e melhorar o processo de cuidar dos pacientes oncológicos.

Portanto, é valido reforçar a importância de se pensar na criação, de espaços para o compartilhamento de experiências difíceis que circulam nos ambientes oncológicos, essa interação ajudará o profissional a não se sentir sozinho, os enfermeiros que atuam em oncologia, necessitam receber apoio psicológico e suporte emocional por parte do hospital em que trabalham, e maior preparo durante a graduação, para que assim possam lidar com os sentimentos dos outros e com suas próprias emoções. -

\section{REFERÊNCIAS}

1. Silva MEDC, Silva LDC, Dantas ALB, Araujo DOR; Duarte IS; Assistência de enfermagem ao paciente oncológico no hospital: revisão integrativa, 2013. Disponivel em: http://apps.cofen.gov. br/cbcenf/sistemainscricoes/arquivosTrabalhos/I47669.E11. T9135.D7A P.pdf. Acesso em 12 mar 2017, 23:00

2. Kiuser SR; Terra MG, Noal HC, Lacchini, AJB; Padoin SMM de. Vivencia de uma equipe de enfermagem acerca do cuidado aos pacientes com câncer. Rev. Rene. FORTALEZA, 2011. Disponível em http://www.revistarene.ufc.br/vol12n1_pdf/a22v12n1.pdf. Acesso em: 18 fev 2017 16:44:20.

3. Menegócio AM, Rodrigues L, Teixeira GL, Enfermagem Oncologia: Relação de Afetividade ou Meramente Técnica? Ensaios Cienc., Cienc. Biol. Agrar. Saúde, v.19, 2015 Disponível em: http:// www.pgsskroton.com.br/seer/index.php/ensaioeciencia/article/viewFile/3191/2929. Acesso em 14 de jun. 2017 02:00:12.

4. Guia $H_{\text {; }}$ Stresse Profissional e Estratégias de Coping dos Enfermeiros do Serviço de Urgência, Barcarena, 2015. Disponivel em: https://repositório cientifico.uatlantica.pt/bitstream/10884/968/1/Monografia\%20Enfermagem\%20Helena\%20G uia\%20200290137.pdf. Acesso em: 29 jun. 2017, 19:28:00.

5. Guido LA; Linch GF, Pitthan C, Oliveira L; Umann J; Estresse, coping e estado de saúde entre enfermeiros hospitalares,
2011. Disponivel em: http://www.scielo.br/pdf/reeusp/v45n6/ v45n6a22.pdf. Acesso em: 29 jun. 2017, 19:31:00.

6. Rodrigues AB, Chaves EC, Fatores Estressantes e Estratégias de Coping dos Enfermeiros atuantes em Oncologia; Rev Latino-am Enfermagem 2008. Disponivel em: http://www.scielo.br/ pdf/rlae/v16n1/pt_03.pdf. Acesso em 02 out 2017 10:48:23.

7. Lages MGG; Costa MAO de, Lopes TR, Amorim FCS, Neto APA de, Nascimento LRD; Costa CLS, Estratégia de enfrentamento de enfermeiros frente ao paciente oncológico pediátrico, 2011. Disponivel em http://www.inca.gov.br/rbc/n_57/v04/pdf/06_ artigo_estrategias_enfrentamento_enfermeiros_f rente_paciente_oncologico_pediatrico.pdf. Äcesso em 25 mar 2017 15:30:00.

8. Damião EBC, Rossato LM, Fabri LRO de, Dias VC, Inventário de estratégias de enfrentamento: um referencial teórico. 2009 Disponível em: http://www.scielo.br/pdf/reeusp/v43nspe2/ a09v43s2.pdf, Acesso em: 22 nov. 2017, 17:31:00.

9. Oliveira JF de; Estratégias de enfrentamento (Coping) dos familiares de pacientes internados em unidade de terapia intensiva;2007. Disponivel em: http://www.scielo.br/scielo.php?script=sci_nlinks\&ref $=000120 \& p i d$ =S00806234201000020002700013 \&lng=pt Acesso em: 22 nov. 2017, 18:31:00. 